\title{
Factors Associated with Social Support Needs of Spouses of Patients with Cancer: Online Survey
}

\author{
Kanako Amano ${ }^{1,2 *}$, Kanako Ichikura1,3, Kazuho Hisamura4, Yuko Motomatsu ${ }^{5}$, \\ Eisuke Matsushima ${ }^{1}$
}

\author{
${ }^{1}$ Section of Liaison Psychiatry and Palliative Medicine, Graduate School of Medical and Dental Sciences, \\ Tokyo Medical and Dental University, Tokyo, Japan \\ ${ }^{2}$ Palliative care ward, Heiwa Hospital, Kanagawa, Japan \\ ${ }^{3}$ Department of Health Science, School of Allied Health Sciences, Kitasato University, Kanagawa, Japan \\ ${ }^{4}$ Department of Medical Oncology, Kanazawa Medical University, Ishikawa, Japan \\ ${ }^{5}$ Nursing Department, Tokyo Medical and Dental University Hospital, Tokyo, Japan \\ Email: *kanalppm@tmd.ac.jp, kanakoamano1028@hotmail.com
}

\author{
How to cite this paper: Amano, K., Ichi- \\ kura, K., Hisamura, K., Motomatsu, Y. and \\ Matsushima, E. (2019) Factors Associated \\ with Social Support Needs of Spouses of \\ Patients with Cancer: Online Survey. In- \\ ternational Journal of Clinical Medicine, \\ 10, 270-292. \\ https://doi.org/10.4236/ijcm.2019.104021 \\ Received: March 4, 2019 \\ Accepted: April 13, 2019 \\ Published: April 16, 2019 \\ Copyright $\odot 2019$ by author(s) and \\ Scientific Research Publishing Inc. \\ This work is licensed under the Creative \\ Commons Attribution International \\ License (CC BY 4.0). \\ http://creativecommons.org/licenses/by/4.0/ \\ (c) (i) Open Access
}

\begin{abstract}
Background: A means of assessing the social support needs of spouses of patients with cancer is not available in Japan, yet such individuals are at increased risk of developing psychological difficulties. Objectives: The present study aimed (1) to describe the social support needs of spouses of patients with cancer, and (2) to explore factors associated with social support needs of spouses of patients with cancer. Design: Spouses $(n=559)$ of patients with cancer were recruited by registered agents of an online survey company and completed a self-reporting, online questionnaire. Measurements: The questionnaires included demographic information and a tool to assess social support needs. Results: Factor analysis of social support needs of the spouses of patients with cancer indicated that (1) "social support needs regarding disease and treatment of patient" (54 items) comprised 3 factors ("medical condition and cure", "daily life and social support", "intimacy and employment"), and (2) "social support needs of spouse (19 items)" comprised 2 factors ("family psychological issues and social support" and "intimacy, employment and society"). The ANOVA and T tests showed that "younger age", "under treatment", and "cancer not cured: treatment stopped", "PS1" and "PS 2-4", the presence of "lung cancer", and "recurrence/metastasis" were significant factors (all $\mathrm{p}<0.05)$. Conclusions: The age of the spouse, treatment status, performance status, site of cancer, and recurrence/metastasis are important factors related to spousal needs for social support. Clinicians should assess these factors and the social support needs of spouses to provide appropriate support.
\end{abstract}




\section{Keywords}

Cancer, Spouse, Social Support Needs, Assessment Tool, Online Survey

\section{Introduction}

Spouses and partners of cancer patients have an increased risk of psychological difficulties, such as depression, anxiety, impaired self-esteem, somatic complaints, and difficulties experienced within the couple [1] [2] [3] [4]. Psychological distress experienced by spouses continues after the death of the patient. One predictor of higher risk for developing complicated grief is the loss of a spouse [5] [6] [7], and caregivers of patients with cancer have a higher level of depressive symptoms after bereavement if they were the patient's spouse [8]. The assessment of spousal needs is a critical step for determining appropriate support and providing high-quality care to reduce psychological distress between spouses.

Some countries have tools to assess support needs for partners and caregivers of patients with cancer, such as the Supportive Care Needs Survey-Partners and Caregivers (SCNS-P \& C) in Australia [9], a comprehensive needs assessment tool for cancer caregivers (CNAT-C) in Korea [10], and the Cancer Survivors' Partners Unmet Needs measure (CaSPUN) [11]. However, a tool for assessing the needs of spouses of patients with cancer is not available in Japan. Nevertheless, it is difficult to use other instruments from other countries after translation, because social support needs reflect factors in the social environment, such as perceptions and emotions related to cancer, healthcare systems, social welfare policies, and work systems. Thus, instead of translating other instruments from other countries, we decided to develop an original tool to assess social support needs for spouses in Japan to provide specific care for individual spousal needs.

One assessment of social issues of Japanese patients with cancer showed that $51.1 \%$ of them had experienced some type of social issues within the past five years [12]. Another survey demonstrated that the prevalence of unmet supportive care needs among Japanese cancer survivors was high in medical-psychological and financial domains and relatively low in physical and sexual domains [13]. However, caregiver needs were not highly correlated with patient needs, implying that caregivers have their own needs, and that a separate assessment of caregiver need is needed [10]. Therefore, we aimed to describe social support needs of spouses of patients with cancer based on the Social Problem Checklist (SPC) for Japanese patients with cancer [12] [14] and explore factors associated with social support needs of spouses of patients with cancer.

\section{Methods}

\subsection{Participants}

We conducted an online survey of 559 spouses of cancer patients between No- 
vember 10th and 29th 2016. The eligibility criteria were as follows: recruited by registered agents of an online survey company (Macromill Inc., Tokyo, Japan), age $>20$ years, spouses of patients diagnosed with cancer within the past five years, experienced difficulties regarding disease and treatment of the patient at home, in the workplace, and the neighborhood, able to understand details of this study, able to respond to an online survey, and uninformed about eligibility criteria (to exclude bias before the online survey) (Figure 1).

\subsection{Procedures}

Macromill designed the online questionnaire as "the disease survey". Check boxes and radio buttons were used for each item to answer.

Agents at Macromill were informed about the study purpose and recruited eligible participants online. Agents were paid with points in return for participating in this investigation. They could earn points if they answered all questions, and then they could exchange points for cash, gift certificates, merchandise, or points of business partners.

This study was approved by the ethics committee of the Tokyo Medical and Dental University (M2015-581). The return of completed forms was considered consent. It was explained that participants could stop answering the questionnaire when they did not want to answer.

Participants completed the online self-reporting questionnaires, which included 23 items of spousal demographic data and 146 items regarding social issues and social support needs of spouses of patients with cancer.

\subsection{Measured Items}

\subsubsection{Demographic and Medical Information}

The demographic data including sex, age, province, children, annual household income, personal income, spousal occupation, site of cancer, previous treatment, treatment status, recurrence/metastasis, performance status, types of previous and present medical facilities, housemate, and housemate other than spouse.

\subsubsection{Tool to Assess Social Support Needs of Spouses of Patients with Cancer (73 Items)}

We developed a tool with which to assess social issues of spouses of Japanese patients with cancer ( 82 items) based on the SPC for Japanese patients with cancer (60 items) [12] [14] because measures of social issues and support needs developed in other countries were not appropriate for Japanese spouses of patients with cancer.

We confirmed the content validity of the original assessment tool of social issues (82 items) in an initial multidisciplinary meeting that included a psychiatrist, a medical social worker, two clinical psychologists, and a certified palliative care nurse in June 2015. Thereafter, we constructed an original scale of social issues and social support needs for the spouses of Japanese patients with cancer (164 items). 


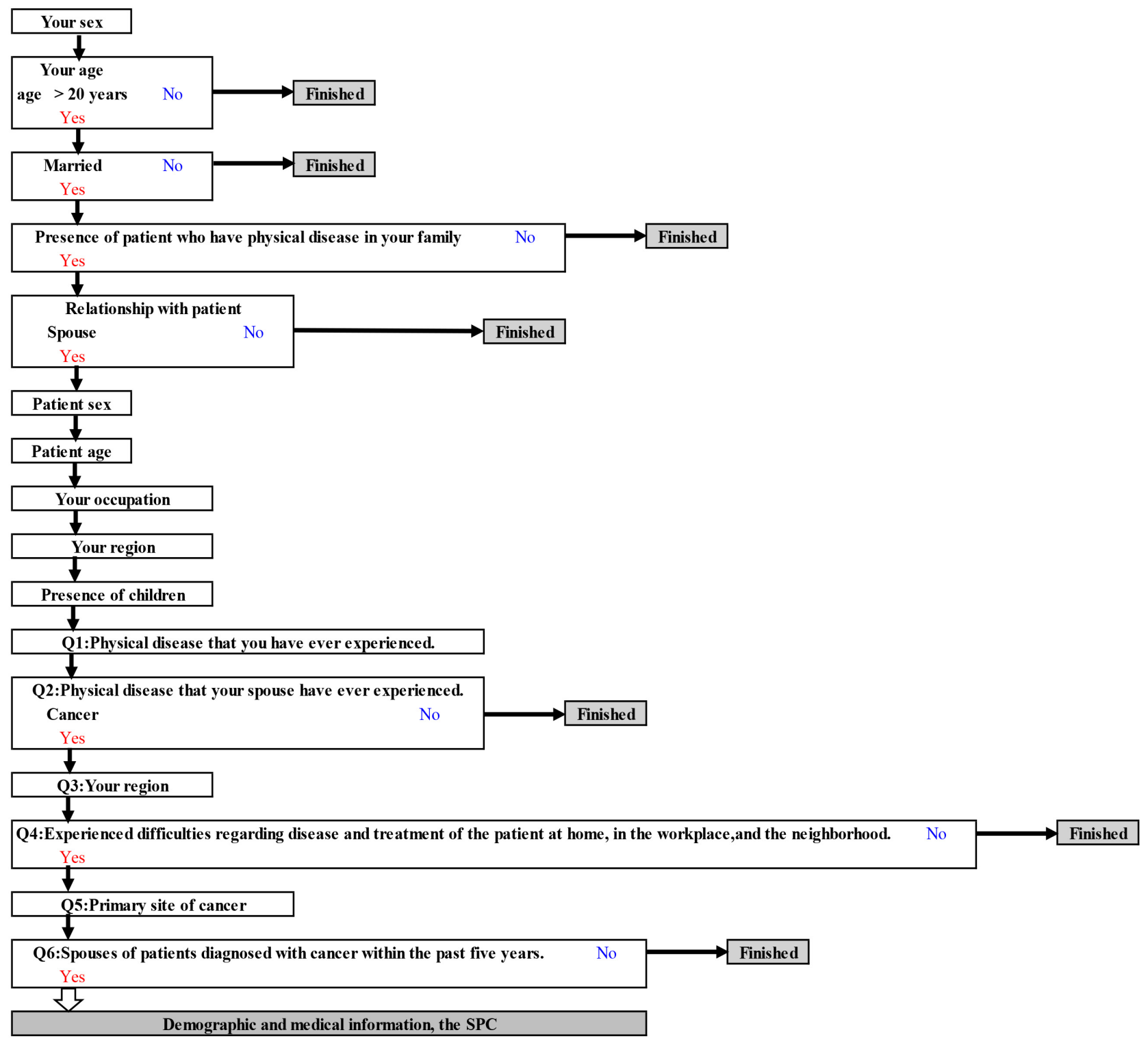

Figure 1. Flow diagram of the process to select participants.

Factor analysis based on Promax rotation using the maximum likelihood method was applied to the scale of social issues and social support needs for the spouses, and 146 items were extracted.

The content validity of this original assessment tool of social issues and social support needs for the spouses of patients with cancer (146 items) was addressed at a second multidisciplinary meeting including a psychiatrist and two clinical psychologists in February 2017. The present article focuses on the 73 social support needs items of these 146 items (Figure 2).

The participants were asked if they had needed any supports regarding each item during the past month to rate the level of severity on a 6-point Likert scale, which ranged from 1 (very much) to 2 (quite a lot), 3 (a little), 4 (solved by myself), 5 (extremely satisfied), or 6 (not applicable). 


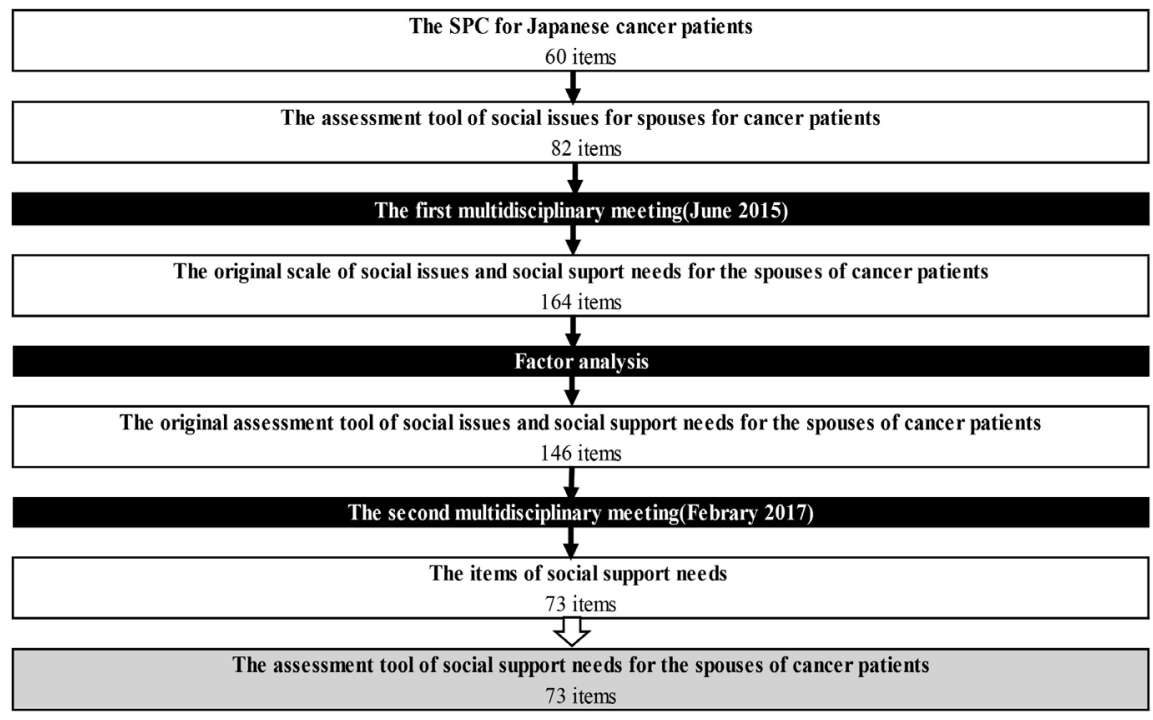

Figure 2. Flow diagram of the process to make the assessment tool.

After a multidisciplinary meeting including a psychiatrist, two clinical psychologists, and a medical social worker to evaluate the assessment tool of social support needs of the spouses of cancer patients, each response category was scored as follows: 4 (very much), 3 (quite a lot), 2 (a little), 1 (solved by myself, extremely satisfied), or 0 (not applicable). A rating $\geq 3$ was regarded as a serious need for social support.

\subsection{Statistical Analysis}

The demographic and medical information of the participants is summarized using descriptive statistics.

We modified the 60-item SPC for Japanese patients with cancer [12] [14] and developed an original scale of 164 items regarding social issues and social support needs of their spouses. Factor analysis based on Promax rotation using the maximum likelihood method extracted 146 items regarding social issues and the social support needs of the spouses of patients with cancer.

Differences among three age groups, three performance status groups, and three groups with previous treatment were assessed using ANOVA.

Differences among sex, cancer site, previous treatment, presence of recurrence/metastasis, type of previous and present medical facilities, and housemate other than spouse were evaluated using T-tests. All data were statistically analyzed using SPSS version 23.0 (IBM, Armonk, NY, USA).

\section{Results}

\subsection{Demographic and Medical Information of Participants}

We distributed online questionnaires to 699 agents of Macromill and analyzed 559 that were returned (valid response rate, $80.0 \%$ ). Table 1 shows the characteristics and medical information of the participants. 
Table 1. Demographic and clinical characteristics of participants $(n=559)$.

\begin{tabular}{|c|c|}
\hline Variables & Means \pm SD or $n(\%)$ \\
\hline Male spouse & $339(60.6 \%)$ \\
\hline Patient age $(y)$ & $55.1 \pm 12.5$ \\
\hline $20 \mathrm{~s}$ & $13(2.3 \%)$ \\
\hline $30 \mathrm{~s}$ & $54(9.7 \%)$ \\
\hline $40 \mathrm{~s}$ & $116(20.75 \%)$ \\
\hline $50 \mathrm{~s}$ & $152(27.2 \%)$ \\
\hline$\geq 60$ & $224(40.1 \%)$ \\
\hline Spouse age $(y)$ & $54.9 \pm 12.7$ \\
\hline $20 \mathrm{~s}$ & $19(3.4 \%)$ \\
\hline $30 \mathrm{~s}$ & $50(8.9 \%)$ \\
\hline 40 s & $109(19.5 \%)$ \\
\hline $50 \mathrm{~s}$ & $166(29.7 \%)$ \\
\hline$\geq 60$ & $215(38.5 \%)$ \\
\hline \multicolumn{2}{|l|}{ Primary site of cancer } \\
\hline \multicolumn{2}{|l|}{ (multiple answers) } \\
\hline Breast & $139(24.9 \%)$ \\
\hline Colon & $95(17.0 \%)$ \\
\hline Stomach & $62(11.1 \%)$ \\
\hline Lung & $59(10.6 \%)$ \\
\hline Malignant lymphoma & $34(6.1 \%)$ \\
\hline Prostate & $28(5.0 \%)$ \\
\hline Uterine & $20(3.6 \%)$ \\
\hline Liver & $18(3.2 \%)$ \\
\hline Thyroid & $18(3.2 \%)$ \\
\hline Kidney & $17(3.0 \%)$ \\
\hline Esophagus & $17(3.0 \%)$ \\
\hline Bladder & $16(2.9 \%)$ \\
\hline Head, neck, oral & $13(2.3 \%)$ \\
\hline Pancreas & $12(2.1 \%)$ \\
\hline Leukemia & $10(1.8 \%)$ \\
\hline Other & $55(9.8 \%)$ \\
\hline \multicolumn{2}{|l|}{ Previous treatment } \\
\hline Surgery & $455(81.4 \%)$ \\
\hline Radiation & $180(32.2 \%)$ \\
\hline Chemotherapy or hormone therapy & $233(41.7 \%)$ \\
\hline Folk remedy & $6(1.1 \%)$ \\
\hline Other & $30(5.4 \%)$ \\
\hline
\end{tabular}




\section{Continued}

\begin{tabular}{cc}
\hline Treatment status & \\
\hline Under treatment & $233(41.7 \%)$ \\
Cancer cured; treatment completed & $274(49.0 \%)$ \\
Cancer not cured; treatment stopped & $29(5.2 \%)$ \\
Other situations & $23(4.1 \%)$ \\
\hline Recurrence/metastasis & $136(24.3 \%)$ \\
\hline Yes & $322(57.6 \%)$ \\
\hline Performance status & $163(29.2 \%)$ \\
\hline PS0 & $31(5.5 \%)$ \\
PS1 & $20(3.6 \%)$ \\
PS2 & $23(4.1 \%)$ \\
\hline PS4 & \\
\hline
\end{tabular}

Types of previous and present medical facilities

(Multiple answers)

Special hospital for cancer

$109(19.5 \%)$

General hospital

$388(69.4 \%)$

Regional hospital

$84(15.0 \%)$

Local clinic

$10(1.8 \%)$

Other

$8(1.4 \%)$

Unclear

$4(0.7 \%)$

\section{Children}

\begin{tabular}{cc}
\hline Yes & $100(17.9 \%)$ \\
\hline Housemate & $552(98.7 \%)$ \\
\hline Living together & $7(1.3 \%)$ \\
Living apart & \\
\hline Housemate other than spouse & $327(58.5 \%)$ \\
\hline Yes & $27(4.8 \%)$ \\
\hline Province & $32(5.7 \%)$ \\
\hline Hokkaido region & $165(29.5 \%)$ \\
Touhoku region & $116(20.8 \%)$ \\
Kantou region & $100(17.9 \%)$ \\
Cyubu region & $41(7.3 \%)$ \\
Kinki region & $13(2.3 \%)$ \\
Cyugoku region & $65(11.6 \%)$ \\
Shikoku region & \\
Kyusyu region & \\
\hline
\end{tabular}




\section{Continued}

\begin{tabular}{|c|c|}
\hline Annual household income & \\
\hline Under 2 million & $17(3.0 \%)$ \\
\hline 2 - under 4 million & $112(20.0 \%)$ \\
\hline 4 - under 6 million & $156(27.9 \%)$ \\
\hline 6 - under 8 million & $100(17.9 \%)$ \\
\hline 8 - under 10 million & $54(9.7 \%)$ \\
\hline 10 - under 12 million & $21(3.8 \%)$ \\
\hline 12 - under 15 million & $17(3.0 \%)$ \\
\hline 15 - under 20 million & $17(3.0 \%)$ \\
\hline 20 million and over & $9(1.6 \%)$ \\
\hline Unclear & $29(5.2 \%)$ \\
\hline Non-response & $27(4.8 \%)$ \\
\hline \multicolumn{2}{|l|}{ Personal income } \\
\hline Under 2 million & $188(33.6 \%)$ \\
\hline 2 - under 4 million & $122(21.8 \%)$ \\
\hline 4 - under 6 million & $87(15.6 \%)$ \\
\hline 6 - under 8 million & $57(10.2 \%)$ \\
\hline 8 - under 10 million & $25(4.5 \%)$ \\
\hline 10 - under 12 million & $15(2.7 \%)$ \\
\hline 12 - under 15 million & $7(1.3 \%)$ \\
\hline 15 - under 20 million & $3(0.5 \%)$ \\
\hline 20 million and over & $2(0.4 \%)$ \\
\hline Unclear & $23(4.1 \%)$ \\
\hline Non-response & $30(5.4 \%)$ \\
\hline \multicolumn{2}{|l|}{ Spousal occupation } \\
\hline Civil servant & $16(2.9 \%)$ \\
\hline Manager \& Executive & $18(3.2 \%)$ \\
\hline Office worker (Cletical work) & $70(12.5 \%)$ \\
\hline Office worker (Technical work) & $65(11.6 \%)$ \\
\hline Office worker (Other) & $62(11.1 \%)$ \\
\hline Indipendent business & $42(7.5 \%)$ \\
\hline Liberal profession & $8(1.4 \%)$ \\
\hline Homemaker & $118(21.1 \%)$ \\
\hline Part time job & $60(10.7 \%)$ \\
\hline Student & $1(0.2 \%)$ \\
\hline Other & $27(4.8 \%)$ \\
\hline Unemployed & $72(12.9 \%)$ \\
\hline
\end{tabular}


The spouses were divided into young (age 20s and 30s; $\mathrm{n}=69,12.3 \%$ ), middle-aged (age 40s and 50s; $\mathrm{n}=275,49.2 \%$ ), and elderly (age $\geq 60 \mathrm{~s} ; \mathrm{n}=215$, $38.5 \%)$ groups. The primary sites of cancer comprised breast $(\mathrm{n}=139,24.9 \%)$, colon $(\mathrm{n}=95,17.0 \%)$, stomach $(\mathrm{n}=62 ; 11.1 \%)$, lung $(\mathrm{n}=59,10.6 \%)$, and malignant lymphoma $(n=34,6.1 \%)$. The types of therapy were surgery $(n=455$, $81.4 \%)$ and chemotherapy or hormonal therapy $(\mathrm{n}=233,41.7 \%)$. The cancer had been cured and treatment had been completed in 274 (49.0\%) patients, and 233 (41.7\%) were still undergoing treatment.

\subsection{Factors Related to Social Support Needs}

\subsubsection{Factors Related to Social Support Needs Regarding Disease and Treatment of Patients}

Factor analysis identified three factors among 54 items (Table 2).

Former items 1, 24, 36, 46 and 47 did not load $<0.1$ about the differences of factor loading between factors and were excluded (Appendix A).

A psychiatrist and a clinical psychologist at a multidisciplinary meeting discussed the items that were included in different factors between the assessment tools of social issues and of social support needs and excluded former item 59 (the number before exclusion) that did not differ highly in factor loading between factors.

\subsubsection{Factors Related to Social Support Needs of Spouses}

Factor analysis identified two factors among 19 items (Table 3).

Former item 22 did not load $<0.1$ about the differences of factor loading between factors and was excluded (Appendix B).

A psychiatrist and a clinical psychologist at a multidisciplinary meeting discussed the items that were included in different factors between the assessment tools of social issues and of social support needs and excluded former items 16 and 18 (numbers before exclusion) that did not significantly differ between factors.

\subsection{Factors Associated with Social Support Needs of Spouses of Patients with Cancer}

Table 4 shows that scores were higher across all scales and factors of social support needs in younger than in middle-aged and elderly spouses $(\mathrm{p}<0.05)$.

Among the most prevalent of the primary cancer sites, namely lung cancer (10.6\%), stomach cancer (11.1\%), colon cancer (17.0\%) and breast cancer (24.9\%), only lung cancer significantly differed in terms of social support needs regarding "patient disease and treatment" and "spouse difficulties" (both $\mathrm{p}<$ 0.05).

Table 5 shows that Factor 1, "medical condition and cure" and 2, "daily life and social support" were significantly higher ( $\mathrm{p}<0.05$ for both) in the measure of "patient disease and treatment" for patients with than without lung cancer. Factor 1, "family psychological issues and social support", was also significantly 
Table 2. Factors of social support needs regarding disease and treatment of patients.

Q: Due to patient's disease and treatment, have you ever needed some support (e.g., advice, information and services from professionals and patients under similar circumstances) during the past month regarding the following items?

\begin{tabular}{|c|c|c|c|c|}
\hline & Items & Factor 1 & Factor 2 & Factor 3 \\
\hline & & $\begin{array}{l}\text { Medical condition } \\
\text { and Cure }\end{array}$ & $\begin{array}{l}\text { Daily life and } \\
\text { Social Support }\end{array}$ & $\begin{array}{l}\text { Intimacy and } \\
\text { Employment }\end{array}$ \\
\hline 1 & Insufficient information regarding how to take care of patient from now on & 0.938 & -0.007 & -0.034 \\
\hline 2 & $\begin{array}{l}\text { Insufficient information about the methods, contents, and results of medical } \\
\text { examinations for patient }\end{array}$ & 0.935 & 0.009 & -0.044 \\
\hline 3 & $\begin{array}{l}\text { Insufficient information regarding patient's current and prospective medical condi- } \\
\text { tions }\end{array}$ & 0.933 & -0.021 & -0.002 \\
\hline 4 & Insufficient explanation from medical staff regarding treatment plans and policies & 0.909 & -0.055 & 0.072 \\
\hline 5 & Insufficient information about patient's various treatment plan & 0.890 & 0.030 & -0.021 \\
\hline 6 & $\begin{array}{l}\text { Insufficient information regarding how to cope with patient's treatment side effects } \\
\text { and disease symptoms }\end{array}$ & 0.865 & 0.028 & 0.011 \\
\hline 7 & $\begin{array}{l}\text { Insufficient explanation concerning the benefits and side effects of treatments from } \\
\text { medical staff before you decide to have them }\end{array}$ & 0.858 & 0.107 & -0.059 \\
\hline 8 & Insufficient information regarding patient's appropriate nutrition and diet & 0.856 & 0.016 & 0.031 \\
\hline 9 & $\begin{array}{l}\text { Insufficient information regarding how to obtain informations about patient's } \\
\text { disease and treatment }\end{array}$ & 0.844 & 0.087 & -0.024 \\
\hline 10 & $\begin{array}{l}\text { Choosing which hospital (or doctor) patient should visit to receive medical treatment } \\
\text { and examination }\end{array}$ & 0.823 & 0.093 & -0.037 \\
\hline 11 & $\begin{array}{l}\text { Insufficient information concerning how to cope with patient's anxiety and depres- } \\
\text { sive mood }\end{array}$ & 0.773 & 0.159 & -0.025 \\
\hline 12 & Patient's difficulties in openly communicating with his/her doctor & 0.758 & 0.108 & 0.057 \\
\hline 13 & $\begin{array}{l}\text { Poor communication among health care staff to coordinate patient's medical treat- } \\
\text { ment and care(e.g., doctor in charge, other doctor, family doctor, and nurse) }\end{array}$ & 0.746 & -0.008 & 0.165 \\
\hline 14 & $\begin{array}{l}\text { Insufficient information regarding patient's palliative medicine and care that de- } \\
\text { crease distress, such as pain }\end{array}$ & 0.745 & 0.039 & 0.122 \\
\hline 15 & $\begin{array}{l}\text { Not being assured that patient's current hospital (or patient's home doctor) would } \\
\text { provide advice to him/her when patient have sudden physical problems at home }\end{array}$ & 0.745 & 0.124 & -0.013 \\
\hline 16 & $\begin{array}{l}\text { Having patient's physical problems doesn't treated immediately by medical staff } \\
\text { (e.g., doctor, nurse) }\end{array}$ & 0.714 & 0.105 & 0.076 \\
\hline 17 & $\begin{array}{l}\text { Little sympathy and support concerning patient's psychological issues from medical } \\
\text { staff }\end{array}$ & 0.708 & -0.013 & 0.189 \\
\hline 18 & $\begin{array}{l}\text { Consulting with another specialist besides patient's doctor about his/her disease and } \\
\text { treatment }\end{array}$ & 0.650 & 0.233 & -0.080 \\
\hline 19 & $\begin{array}{l}\text { Having no particular clinic and doctor patient or family can consult with when pa- } \\
\text { tient and family need to }\end{array}$ & 0.649 & 0.239 & -0.018 \\
\hline 20 & $\begin{array}{l}\text { Insufficient information regarding patients' complementary and alternative medicine } \\
\text { (e.g., health foods, hot spring, and qigong) }\end{array}$ & 0.628 & 0.121 & 0.117 \\
\hline 21 & $\begin{array}{l}\text { Having access to professional psychological counseling whenever patient and } \\
\text { you need it }\end{array}$ & 0.507 & 0.317 & 0.015 \\
\hline 22 & Getting to, entering, leaving, or changing a patient's hospital & 0.473 & 0.292 & 0.061 \\
\hline 23 & Imposing a patient's burden on his/her family & -0.073 & 0.902 & 0.059 \\
\hline 24 & $\begin{array}{l}\text { Difficulties in patient's dealing with anxiety and worry among his/her family mem- } \\
\text { bers }\end{array}$ & 0.099 & 0.859 & -0.035 \\
\hline
\end{tabular}




\section{Continued}

25 Difficulties enjoying patient's hobbies, recreations and social activities as before because of his/her disease and treatment

\begin{tabular}{|c|c|c|}
\hline 0.093 & 0.844 & -0.042 \\
\hline-0.038 & 0.834 & 0.041 \\
\hline 0.028 & 0.828 & 0.045 \\
\hline 0.034 & 0.822 & -0.073 \\
\hline 0.120 & 0.808 & -0.054 \\
\hline 0.103 & 0.786 & -0.025 \\
\hline 0.099 & 0.765 & 0.009 \\
\hline 0.182 & 0.744 & -0.064 \\
\hline 0.230 & 0.643 & 0.051 \\
\hline 0.144 & 0.642 & 0.146 \\
\hline 0.114 & 0.630 & 0.117 \\
\hline 0.102 & 0.618 & 0.197 \\
\hline 0.051 & 0.608 & 0.160 \\
\hline 0.298 & 0.608 & 0.016 \\
\hline 0.156 & 0.599 & 0.143 \\
\hline 0.107 & 0.571 & 0.258 \\
\hline 0.231 & 0.559 & 0.123 \\
\hline 0.196 & 0.516 & 0.176 \\
\hline 0.255 & 0.505 & 0.182 \\
\hline 0.237 & 0.502 & 0.179 \\
\hline 0.151 & 0.499 & 0.260 \\
\hline 0.084 & 0.492 & 0.333 \\
\hline 0.307 & 0.477 & 0.104 \\
\hline-0.010 & -0.033 & 0.996 \\
\hline-0.005 & -0.046 & 0.990 \\
\hline-0.003 & 0.018 & 0.906 \\
\hline 0.029 & 0.135 & 0.781 \\
\hline 0.063 & 0.054 & 0.732 \\
\hline 0.005 & 0.321 & 0.583 \\
\hline 0.023 & 0.250 & 0.562 \\
\hline
\end{tabular}

27 Patient's difficulties performing his/her responsibilities in the house

8 Medical and living expenses while receiving treatment

Difficulties in having sufficient support available to you (e.g., assistance and public service from people around you)

30 Planning patient's own and your future life

31 Taking care of family (e.g., childrearing, nursing parents and spouse)

32 Insur Insufficient information concerning patient's social welfare services (e.g., nursing

care insurance program, welfare system for the disabled)

33 Patient's having no one with a similar experience to talk to

34 Relationship and communication with patient's friends and persons close to patient

35 Changes of patient's figure and appearance(e.g., increasing and decreasing of weight)

6 Relationship and communication with patient's neighbors

37 Using financial services(e.g., loans, health care and life insurance)

38

Having no one and place to go for advice regarding patient's disease and medical treatment life

39 Relationship and communication with your spouse

Talking about patients disease with people in the patient's workplace and other social places

41 Patient's being socially isolated

42

Insufficient information concerning living supports for patient receiving cancer

Itreatment (e.g., medical wig, elastic stockings, wheelchair, adjustable medical bed)

43 Difficulties in having enough understanding and cooperation from patient's family regarding patient's disease and treatment

44 Talking about patient's disease with patient

45 Being excessively concerned about patient by you

46

Patient's taking care of domestic chores (e.g. cleaning, watching, cooking, grocery shopping)

47 Patient's looking after himself/herself (e.g., eating, bathing, excreting, dressing)

48 Being demoted and assigned a lower position in the patient's workplace

49 Difficulties in getting a promotion and advancing patient's career

50 Being urged to resign and lose patient's job

Difficulty with asking for time off from patient's work for medical treatment (or school if patient is a student)

52 Issues with patient's pregnancy and childbirth

Difficulty with returning and maintaining to patient's work (or education if he/she is a student)

54 Matters concerning your sexual life

\section{Factor 1}

Inter-factor correlation

Factor 2

Factor 3
$0.898^{* *}$

$0.733^{* *}$
$0.814^{* *}$

Factor extraction method: maximum likelihood method; Factor rotation method: Promax; Number of rotation: 4 ; Factor loadings $>0.25$; ${ }^{\star *} \mathrm{p}<0.01$. 
Table 3. Factors of social support needs for spouses.

Q: Have you ever needed support for yourself (e.g., advice, information and services from professionals and patients under similar circumstances) during past month regarding the following items?

\begin{tabular}{|c|c|c|c|}
\hline \multicolumn{2}{|r|}{ Items } & \multirow{2}{*}{$\begin{array}{c}\text { Factor1 } \\
\text { Family's psychological } \\
\text { issue and Social support }\end{array}$} & \multirow{2}{*}{$\begin{array}{c}\text { Factor2 } \\
\text { Intimacy, Employmen } \\
\text { and Society }\end{array}$} \\
\hline & & & \\
\hline 1 & Difficulties in dealing with your anxiety and worry as family & 1.044 & -0.175 \\
\hline 2 & $\begin{array}{l}\text { Having no one and place to go for advice for you regarding patient's disease and } \\
\text { medical treatment life }\end{array}$ & 0.859 & 0.031 \\
\hline 3 & Feeling burden as family & 0.855 & 0.051 \\
\hline 4 & $\begin{array}{l}\text { Insufficient information concerning how to cope with your anxiety and depressive } \\
\text { mood as family }\end{array}$ & 0.849 & -0.051 \\
\hline 5 & Having no one with a similar experience to talk to & 0.829 & 0.072 \\
\hline 6 & Difficulties performing your responsibilities in the house & 0.792 & 0.108 \\
\hline 7 & $\begin{array}{l}\text { Difficulties enjoying your hobbies, recreations and social activities as before because } \\
\text { of patient disease and treatment }\end{array}$ & 0.762 & 0.108 \\
\hline 8 & Taking care of domestic chores (e.g., cleaning, washing, cooking, grocery shopping) & 0.750 & 0.080 \\
\hline 9 & Being socially isolated & 0.738 & 0.168 \\
\hline 10 & Relationship and communication with your friends and persons close to you & 0.666 & 0.259 \\
\hline 11 & $\begin{array}{l}\text { Little sympathy and support concerning your psychological issues from medical } \\
\text { staff }\end{array}$ & 0.642 & 0.157 \\
\hline 12 & Talking about patient's disease in your work place and other social places & 0.592 & 0.340 \\
\hline 13 & Relationship and communication with your neighbors & 0.553 & 0.394 \\
\hline 14 & Being excessively concerned about you by patient & 0.533 & 0.375 \\
\hline 15 & $\begin{array}{l}\text { Being demoted and assigned a lower position in your workplace because of patients } \\
\text { disease }\end{array}$ & -0.068 & 1.010 \\
\hline 16 & $\begin{array}{l}\text { Difficulties in getting a promotion and advancing in your workplace because of } \\
\text { patient's disease }\end{array}$ & -0.086 & 0.991 \\
\hline 17 & Being urged to resign and lose your work & -0.058 & 0.951 \\
\hline 18 & Issues with your pregnancy and childbirth & 0.063 & 0.753 \\
\hline 19 & Facing discriminatory treatment because of patient's disease & 0.291 & 0.666 \\
\hline \multirow{2}{*}{\multicolumn{2}{|c|}{ Inter-factor correlation }} & & \\
\hline & & $0.760^{\star *}$ & \\
\hline
\end{tabular}

Factor extraction method: maximum likelihood method; Factor rotation method: Promax; Number of rotation: 3; Factor loadings $>0.25$; ${ }^{* *}$ p $<0.01$.

higher $(\mathrm{p}<0.05)$ in the measure of "spouse difficulties" for patients with than without lung cancer.

All scales and factors of social support needs were significantly higher for "under treatment" than "cancer cured: treatment completed" $(\mathrm{p}<0.05)$ and for "cancer not cured: treatment stopped" than "cancer cured: treatment completed" $(\mathrm{p}<0.05)$.

Table 6 shows that scores for all factors regarding "patient disease and treatment" were significantly higher for patients with than without recurrence/metastasis $(\mathrm{p}<0.05)$ and "spouse difficulties" $(\mathrm{p}<0.05)$. 
Table 4. Comparisons of mean age and social support needs (ANOVA).

\begin{tabular}{|c|c|c|c|c|c|c|c|c|}
\hline & & & & \multicolumn{3}{|c|}{ Mean(SD) } & \multirow{2}{*}{$\begin{array}{c}\mathrm{F} \\
\text { value }\end{array}$} & \multirow{2}{*}{$\begin{array}{c}\text { Multiple } \\
\text { Comparison }\end{array}$} \\
\hline & & & & $\begin{array}{l}\text { Young } \\
(\mathrm{N}=69)\end{array}$ & $\begin{array}{l}\text { Middle } \\
(\mathrm{N}=275)\end{array}$ & $\begin{array}{l}\text { Elderly } \\
(\mathrm{N}=215)\end{array}$ & & \\
\hline \multirow{7}{*}{$\begin{array}{l}\text { Social Support } \\
\text { Needs }\end{array}$} & \multirow{4}{*}{$\begin{array}{l}\text { Patient disease and } \\
\text { treatment }\end{array}$} & Total & & $85.1(70.7)$ & $51.2(52.2)$ & $48.1(40.4)$ & $14.8^{*}$ & $\mathrm{Y}>\mathrm{M}, \mathrm{Y}>\mathrm{E}$ \\
\hline & & Factor 1 & Medical condition and cure & $36.2(30.2)$ & $23.1(23.5)$ & $23.1(19.7)$ & $9.7^{*}$ & $\mathrm{Y}>\mathrm{M}, \mathrm{Y}>\mathrm{E}$ \\
\hline & & Factor 2 & Daily life and social support & $38.5(32.4)$ & $23.0(24.4)$ & $21.7(19.0)$ & $14.1^{*}$ & $\mathrm{Y}>\mathrm{M}, \mathrm{Y}>\mathrm{E}$ \\
\hline & & Factor 3 & Intimacy and employment & $10.4(9.6)$ & $5.0(6.4)$ & $3.3(5.1)$ & $31.2^{*}$ & $\begin{array}{c}\mathrm{Y}>\mathrm{M}, \mathrm{Y}>\mathrm{E} \\
\quad \mathrm{M}>\mathrm{E}\end{array}$ \\
\hline & \multirow{3}{*}{ Spouse difficulties } & Total & & $30.7(25.1)$ & $14.8(16.9)$ & $13.1(13.3)$ & $30.1^{*}$ & $\mathrm{Y}>\mathrm{M}, \mathrm{Y}>\mathrm{E}$ \\
\hline & & Factor 1 & $\begin{array}{l}\text { Family psychological issues } \\
\text { and social support }\end{array}$ & $23.2(18.5)$ & $12.1(13.2)$ & $11.2(10.8)$ & $23.5^{*}$ & $\mathrm{Y}>\mathrm{M}, \mathrm{Y}>\mathrm{E}$ \\
\hline & & Factor 2 & $\begin{array}{l}\text { Intimacy, employment } \\
\text { and society }\end{array}$ & $7.5(6.9)$ & $2.7(4.4)$ & $1.8(3.3)$ & $44.5^{\star}$ & $\mathrm{Y}>\mathrm{M}, \mathrm{Y}>\mathrm{E}$ \\
\hline
\end{tabular}

${ }^{\star} \mathrm{p}<0.05$. Y, young; $\mathrm{M}$, middle-aged; E, elderly. Ages: $\mathrm{Y}, \mathrm{M}$ and E: 21 - 39, 40 - 59, 60 - 87 years, respectively.

Table 5. Comparisons of mean cancer sites and social support needs ( $\mathrm{T}$ test).

\begin{tabular}{|c|c|c|c|c|c|c|}
\hline & & & & & & \\
\hline & & & & Lun & ncer & $t$ ratio \\
\hline & & & & $\begin{array}{l}\text { Presence } \\
(\mathrm{N}=59)\end{array}$ & $\begin{array}{l}\text { Absence } \\
(N=500)\end{array}$ & \\
\hline & & Total & & $68.6(53.8)$ & $52.4(51.7)$ & $2.3^{*}$ \\
\hline & Patient disease and & Factor 1 & Medical condition and cure & $30.6(24.6)$ & $24.0(23.2)$ & $2.0^{*}$ \\
\hline & treatment & Factor 2 & Daily life and social support & $31.5(25.2)$ & $23.6(24.0)$ & $2.4^{*}$ \\
\hline Social Support & & Factor 3 & Intimacy and employment & $6.5(7.9)$ & $4.8(6.7)$ & 1.8 \\
\hline & & Total & & $21.5(18.4)$ & $15.5(17.6)$ & $2.5^{\star}$ \\
\hline & Spouse difficulties & Factor 1 & $\begin{array}{l}\text { Family psychological issues and } \\
\text { social support }\end{array}$ & $17.5(14.1)$ & $12.6(13.5)$ & $2.6^{*}$ \\
\hline & & Factor 2 & Intimacy, employment and society & $4.0(5.1)$ & $2.8(4.7)$ & 1.8 \\
\hline
\end{tabular}

${ }^{*} \mathrm{p}<0.05$.

Table 6. Comparisons of mean recurrence/metastasis and social support needs (T test).

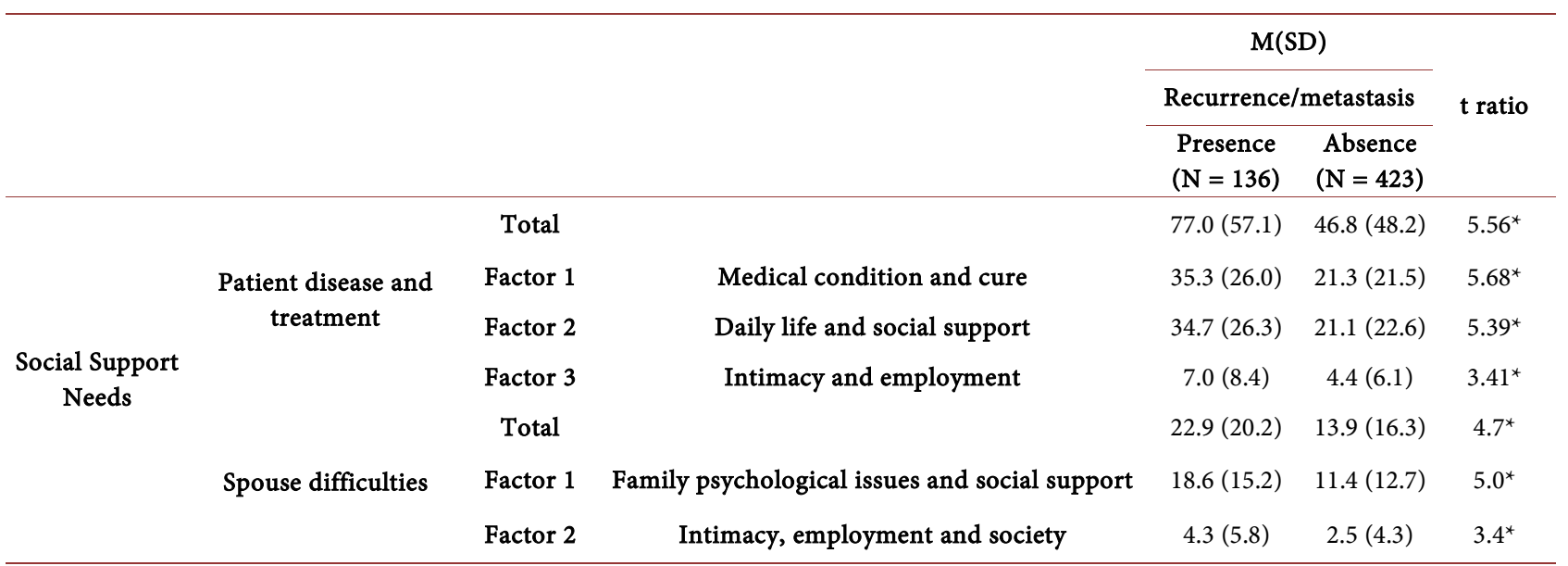

${ }^{*} \mathrm{p}<0.05$ 
"PS1" and "PS 2 - 4" scored higher in all scales and factors of social support needs than "PSO" ( $\mathrm{p}<0.05$ for both).

\section{Conclusions}

The present study described the social support needs of spouses of patients with cancer. This allowed the first systematic and comprehensive needs assessment of these individuals in Japan. Factor analysis identified three underlying domains in "social support needs regarding patient disease and treatment" ("medical condition and cure", "daily life and social support", and "intimacy and employment") and two underlying domains in "social support needs regarding spouse difficulties" ("family psychological issues and social support" and "intimacy, employment and society"). These domains reflect the common needs generally reported in the literature regarding cancer caregivers [10] [11] [15]. One advantage of the present study is that the tool for assessing social support needs focused on the spouses of patients with cancer and identified needs for support with "patient disease and treatment" and "spouse difficulties".

The ANOVA findings showed that the young group scored significantly higher across all scales and factors of social support needs than the middle-aged and elderly groups. In the Adolescent and Young Adult (AYA) population, cancer is the leading cause of death due to illness with the lowest mortality rate, as well as in children, and AYA patients with cancer are growing independently, starting life within the community, and are reaching reproductive age [16]; they have physical changes to become adults and unique psychological issues that are distinct from those of pediatric and older adult patients [16]. Intimacy is harmed more frequently among survivors of breast cancer aged $<45$ years than among those aged $46-54$ and $>55$ years. Psychological problems are more prevalent among younger women who survive breast cancer [17]. AYA cancer patients experienced many specific sequelae after cancer diagnosis and treatment, such as loss of fertility [18] [19], hair loss, and other physical changes and fatigue [20] [21], as well as difficulties with social relationships, employment, educational attainment, and financial burden [22] [23]. Regarding mental health, AYA cancer patients had an increased prevalence of anxiety, depression, and distress than healthy peers and the general public [24] [25]. Additionally, AYA cancer survivors were more likely to have a poorer quality of life than persons of the same age in the general population and older cancer survivors [26]. In young patients, these subjective factors of severity of illness and emotional distress affected posttraumatic stress symptoms and subjective experience of her spouse more [27] [28]. In particular, younger age is a factor associated with high psychological distress and a low quality of life for spouses and partners [29]. The present findings were consistent with those of a previous study of AYA cancer caregivers and indicated that medical staff should consider the social support needs of young spouses more carefully.

Only lung cancer significantly differed among primary cancer sites in patients. 
According to the website of the Cancer Information Service of National Cancer Center in Japan [30], lung cancer had the highest number of fatalities among males and females during 2017. Lung cancer is associated with increased symptomatic distress and unmet needs compared with other types of cancer, with the most common symptoms being fatigue, cough, and dyspnea [31]. Therefore, lung cancer also impacts anxiety and depression among spouses [32] [33]. This result is consistent with previous finding that the most prevalent unmet needs among caregivers of patients with advanced lung cancer were related to information, healthcare service, and daily living [34], and that unmet needs were more prevalent among caregivers of lung cancer survivors at 6 and 24 months after diagnosis [15]. The present study did not find significant differences regarding "intimacy and employment" in disease and treatment of patient and "intimacy, employment and society" in spousal difficulties. Being a young spousal caregiver is a factor of economic burden for the spouse of a patient with lung cancer [35]. In this study, most participants were more than middle-aged, and, therefore, issues of intimacy and employment might have been less important.

It was found that the social support needs were significantly higher among spouses of patients in the "under treatment" than in the "cancer cured: treatment completed" groups and among those of patients in "cancer not cured: treatment stopped" than in "cancer cured: treatment completed" groups. Patients undergoing surgery, chemotherapy, radiation therapy, or chemoradiotherapy experience significant cancer treatment-related fatigue that begins during treatment and decreases following treatment [36], and patients' fatigue might also affect spousal distress and social support needs. For example, the spouses of patients with incurable cancer in the palliative care phase have a higher frequency of depression symptoms [37], and spouses faced with the "cancer not cured: treatment stopped" situation also have many social support needs. Our results are consistent with previous findings and indicate that the spouses of patients with cancer have obvious social support needs, especially when patients undergo treatment or are incurable and treatment has been stopped. Appropriate social support should be provided in such situations.

We also found higher social support needs among spouses of patients with than without recurrence or metastasis, with PS1 than PS0, and with PS 2 to 4 than PS0. Patients who have cancer with poorer performance status might have difficulty coping with the disease and consequently might experience more psychological distress [38]. Therefore, their spouses might also have high levels of need when their patients have low performance status. Indeed, recent studies have suggested that spouses and partners experience physical and psychological distress over the burden of patient care, anxiety, depression, and posttraumatic stress symptoms, and they have to deal with their own lifestyles (such as childcare, missing work, financial burden) when patients are in the terminal phase or developing metastasis and recurrence [37] [39] [40] [41] [42]. Furthermore, caregiver depression, burden, and missing work increase more during the terminal period than during the palliative period [40]. This finding suggests that medical 
staff should assess the social support needs of spouses in these situations to provide adequate support as the functional status of the patient declines.

In conclusion, the age of the spouse, cancer site in the patient, recurrence/metastasis, and performance status are important factors related to the social support needs of spouses. Medical staff should assess the situations of spouses on an individual basis and plan strategies to help reduce unmet needs. Communicating openly with spouses and consulting with health-care professionals could be helpful to fulfill specific social support needs regarding disease and treatment of patients and specific ones of spouses. Providing concrete medical information would be effective to solve needs of disease and treatment of patients. Introducing psychosocial services and self-help groups would be also useful to solve being socially isolated and having no one with a similar experience to talk to. Delivering psychoeducation on relaxation techniques and communication skills with patient, medical staff, people in workplace may improve spouse coping skills to solve psychosocial needs by themselves [43] [44]. Couple-based interventions may also beneficial for spouses to improve relational satisfaction and communication with patients [45] [46].

The most important study limitation is the representativeness of the sample. The participants might have been affected by sampling bias because they were recruited by agents online and, therefore, targeted only persons who were familiar with the internet and specific agents. An online survey that does not reflect whether everything recorded about the patients was correct was used. Distribution of cancer sites was slightly different from that of the general cancer population in Japan. Social support needs might have been underestimated because most participants had good performance status. The second limitation is that our original tool has not been standardized, although its content validity was confirmed in a multidisciplinary meeting.

Despite the limitations, this is the first study to examine the social support needs and their associated factors among spouses of patients with cancer in Japan.

In future research, clinical data about spouses of cancer patients in the hospital setting should be collected. We therefore plan to test the applicability of the assessment tool in hospitals and to explore the social support needs for spouses of patients with cancer in Japan.

\section{Acknowledgements}

The authors would like to sincerely thank the participants, Macromill, and the laboratory staff at Liaison Psychiatry and Palliative Medicine at Tokyo Medical and Dental University.

\section{Conflicts of Interest}

The authors have no conflicts of interest to declare. 


\section{Funding}

This study was financially supported by a donation from a professor emeritus of the Tokyo Institute of Technology, Taizou Iijima and his wife (No. 1713).

\section{References}

[1] Bigatti, S.M., Wagner, C.D., Lydon-Lam, J.R., Steiner, J.L. and Miller, K.D. (2011) Depression in Husbands of Breast Cancer Patients: Relationships to Coping and Social Support. Support Care Cancer, 19, 455-466. https://doi.org/10.1007/s00520-010-0835-8

[2] Braun, M., Mikulincer, M., Rydall, A., Walsh, A. and Rodin, G. (2007) Hidden Morbidity in Cancer: Spouse Caregivers. Journal of Clinical Oncology, 25, 4829-4834. https://doi.org/10.1200/JCO.2006.10.0909

[3] Doorenbos, A.Z., Given, B., Given, C.W., Wyatt, G., Gift, A., Rahbar, M. and Jeon, S. (2007) The Influence of End-of-Life Cancer Care on Caregiver. Research in Nursing \& Health, 30, 270-281. https://doi.org/10.1002/nur.20217

[4] Haun, M.W., Sklenarova, H., Villalbos, M., Thomas, M., Brechtel, A., Löwe, B., Herzog, W. and Hartmann, M. (2014) Depression, Anxiety and Disease-Related Distress in Couples Affected by Advanced Lung Cancer. Lung Cancer, 86, 274-280. https://doi.org/10.1016/j.lungcan.2014.09.009

[5] Chiu, Y.W., Huang, C.T., Yin, S.M., Huang, Y.C., Chien, C.H. and Chuang, H.Y. (2010) Determinants of Complicated Grief in Caregivers Who Cared for Terminal Cancer Patients. Supportive Care Cancer, 18, 1321-1327. https://doi.org/10.1007/s00520-009-0756-6

[6] Fujisawa, D., Miyashita, M., Nakajima, S., Ito, M., Kato, M. and Kim, Y. (2010) Prevalence and Determinants of Complicated Grief in General Population. Journal of Affective Disorders, 127, 352-358. https://doi.org/10.1016/j.jad.2010.06.008

[7] Kersting, A., Bräher, E., Glaesmer, H. and Wagner, B. (2011) Prevalence of Complicated Grief in a Representative Population-Based Sample. Journal of Affective Disorders, 13, 339-343. https://doi.org/10.1016/j.jad.2010.11.032

[8] Ling, S.F., Chen, M.L., Li, C.Y., Chang, W.C., Shen, W.C. and Tang, S.T. (2013) Trajectory and Influencing Factors of Depressive Symptoms in Family Caregivers before and after the Death of Terminally Ill Patients with Cancer. Oncology Nurse Forum, 40, E32-E40. https://doi.org/10.1188/13.ONF.E32-E40

[9] Girgis, A., Lambert, S. and Lecathelinais, C. (2011) The Supportive Care Needs Survey for Partners and Caregivers of Cancer Survivors: Development and Psychometric Evaluation. Psycho-Oncology, 20, 387-393. https://doi.org/10.1002/pon.1740

[10] Shin, D.W., Park, J.-H., Shim, E.-J., Park, J.-H., Choi, J.-Y., Kim, S.G. and Park, E.-C. (2011) The Development of a Comprehensive Needs Assessment Tool for Cancer-Caregivers in Patient-Caregiver Dyads. Psycho-Oncology, 20, 1342-1352. https://doi.org/10.1002/pon.1857

[11] Hodgkinson, K., Butow, P., Hobbs, K.M., Hunt, G.E., Lo, S.K. and Wain, G. (2007) Assessing Unmet Supportive Care Needs in Partners of Cancer Survivors: The Development and Evaluation of the Cancer Supervisors' Partners Unmet Needs Measure (CaSPUN). Psycho-Oncology, 16, 805-813. https://doi.org/10.1002/pon.1138

[12] Hisamura, K. (2010) Problems in Social Lives Patients with Cancer Experience and the Importance of Social Support. Gendai No Esupuri, 517, 41-53. (In Japanese)

[13] Umezawa, S., Fujisawa, D., Fujimori, M., Ogawa, A., Matsushima, E. and Miyashita, 
M. (2015) Prevalence, Associated Factors and Source of Support Concerning Supportive Care Needs among Japanese Cancer Survivors. Psycho-Oncology, 24, 635-642. https://doi.org/10.1002/pon.3702

[14] Hisamura, K., Matsushima, E., Tsukayama, S., Murakami, S. and Motto, Y. (2018) An Exploratory Study of Social Problems Experienced by Ambulatory Patients with Cancer in Japan: Frequency and Association with Perceived Need for Help. Psycho-Oncology, 27, 1704-1710. https://doi.org/10.1002/pon.4703

[15] Girgis, A., Lambert, S.D., McElduff, P., Bonevski, B., Lecathelinais, C., Boyes, A. and Stacey, F. (2013) Some Things Change, Some Things Stay the Same: A Longitudinal Analysis of Cancer Caregivers' Unmet Supportive Care Needs. Psycho-Oncology, 22, 1557-1564. https://doi.org/10.1002/pon.3166

[16] Horibe, K. (2017) Characteristics of Adolescent and Young Adult Cancer. Japanese Journal of Cancer and Chemotherapy, 44, 7-11.

[17] Stava, C.J., Lopez, A. and Vassilopoulou-Sellin, R. (2006) Health Profiles of Younger and Older Breast Cancer Survivors. Cancer, 107, 1752-1759.

https://doi.org/10.1002/cncr.22200

[18] Geue, K., Richter, D., Schmidt, R., Sender, A., Siedentopf, F., Brähler, E. and Stöbel-Richter, Y. (2014) The Desire for Children and Fertility Issues among Young German Cancer Survivors. Journal of Adolescent Health, 54, 527-535. https://doi.org/10.1016/j.jadohealth.2013.10.005

[19] Zerback, B.J., Casillas, J., Nohr, L., Adams, H. and Zeltzer, L.K. (2004) Fertility Issues for Young Adult Survivors of Childhood Cancer. Psycho-Oncology, 13, 689-699. https://doi.org/10.1002/pon.784

[20] Geue, K., Sender, A., Schmidt, R., Richter, D., Hinz, A., Schulte, T., Brähler, E. and Stöbel-Richter, Y. (2014) Gender-Specific Quality of Life after Cancer in Young Adulthood: A Comparison with the General Population. Quality of Life Research, 23, 1377-1386. https://doi.org/10.1007/s11136-013-0559-6

[21] Nowe, E., Stöbel-Richter, Y., Sender, A., Leuteritz, K., Friedrich, M. and Geue, K. (2017) Cancer-Related Fatigue in Adolescents and Young Adults: A Systematic Review of the Literature. Critical Reviews in Oncology/ Hematology, 118, 63-69. https://doi.org/10.1016/j.critrevonc.2017.08.004

[22] Bellizzi, K.M., Smith, A., Schmidt, S., Keegan, T.H.M., Zebrack, B., Lynch, C.F., Deapen, D.D., Shnorhavorian, M., Tompkins, B.J., Simon, M. and the Adolescent and Young Adult Health Outcomes and Patient Experience (AYA HOPE) Study Collaborative Group (2012) Positive and Negative Psychosocial Impact of Being Diagnosed with Cancer as an Adolescent or Young Adult. Cancer, 118, 5155-5162. https://doi.org/10.1002/cncr.27512

[23] Warner, E.L., Kent, E.E., Trevino, K.M., Parsons, H.M., Zebrack, B.J. and Kirchhoff, A.C. (2016) Social Well-Being among Adolescents and Young Adults with Cancer: A Systematic Review. Cancer, 122, 1029-1037. https://doi.org/10.1002/cncr.29866

[24] Dyson, G.J., Thompson, K., Palmer, S., Thomas, D.M. and Schofield, P. (2012) The Relationship between Unmet Needs and Distress amongst Young People with Cancer. Supportive Care Cancer, 20, 75-85. https://doi.org/10.1007/s00520-010-1059-7

[25] Larsson, G., Mattsson, E. and Essen, L.V. (2010) Aspects of Quality of Life, Anxiety, and Depression among Persons Diagnosed with Cancer during Adolescence: A Long-Term Follow-Up Study. European Journal of Cancer, 46, 1062-1068. https://doi.org/10.1016/j.ejca.2010.01.021

[26] Quinn, G.P., Goncalves, V., Sehovic, I., Bowman, M.L. and Reed, D.R. (2015) Quality of Life in Adolescent and Young Adult Cancer Patients: A Systematic Review of 
the Literature. Patient Related Outcome Measures, 6, 19-51.

https://doi.org/10.2147/PROM.S51658

[27] Duprez, C., Vanlemments, L., Untas, A., Antoine, P., Lesur, A., Loustalot, C., Guillement, C., Leclerrcq, M., Segura, C., Carlier, D., Lefeuvre-Plesse, C., Simon, H., Frenel, J.S. and Christophe, V. (2017) Emotional Distress and Subjective Impact of the Disease in Young Women with Breast Cancer and Their Spouses. Future Oncology, 13, 2667-2680. https://doi.org/10.2217/fon-2017-0264

[28] Juth, V., Silver, R.C. and Sender, L. (2015) The Shared Experience of Adolescent and Young Adult Cancer Patients and Their Caregivers. Psycho-Oncology, 24, 1746-1753. https://doi.org/10.1002/pon.3785

[29] Hagedoorn, M., Buunk, B.P., Kuijer, R.G., Wobbes, T. and Sanderman, R. (2000) Couples Dealing with Cancer: Role and Gender Differences Regarding Psychological Distress and Quality of Life. Psycho-Oncology, 9, 232-242. https://doi.org/10.1002/1099-1611(200005/06)9:3<232::AID-PON458>3.0.CO;2-J

[30] The Cancer Information Service of National Cancer Center in Japan. https://ganjoho.jp/reg_stat/statistics/stat/short_pred.html

[31] Sung, M.R., Patel, M.V., Djalalov, S., Le, L.W., Shepherd, F.A., Burkes, R.L., Feld, R., Lin, S., Tudor, R. and Leighl, N.B. (2017) Evolution of Symptom Burden of Advanced Lung Cancer over a Decade. Clinical Lung Cancer, 18, 274-280. https://doi.org/10.1016/j.cllc.2016.12.010

[32] Lee, Y.-H., Liao, Y.-C., Liao, W.-Y., Shun, S.-C., Liu, Y.-C., Chan, J.-C., Yu, C.-J., Yang, P.-C. and Lai, Y.-H. (2013) Anxiety, Depression and Related Factors in Family Caregivers of Newly Diagnosed Lung Patients with Cancer before First Treatment. Psycho-Oncology, 22, 2617-2623. https://doi.org/10.1002/pon.3328

[33] Siminoff, L.A., Wilsom-Genderson, M. and Baker Jr., S. (2010) Depressive Symptoms in Lung Patients with Cancer and Their Family Caregivers and the Influence of Family Environment. Psycho-Oncology, 19, 1285-1293. https://doi.org/10.1002/pon.1696

[34] Chen, S.C., Chiou, S.C., Yu, C.J., Lee, Y.H., Liao, W.Y., Hsieh, P.Y., Jhang, S.Y. and Lai, Y.H. (2016) The Unmet Supportive Care Needs-What Advanced Lung Cancer Patients' Caregivers Need and Related Factors. Supportive Care Cancer, 24, 2999-3009. https://doi.org/10.1007/s00520-016-3096-3

[35] Kavanaugh, M., Kramer, B.J., Walsh, M.C. and Trentham-Dietz, A. (2015) Factors Contributing to Economic Burden in Lung Cancer Spousal Caregivers. Palliative \& Supportive Care, 13, 691-700. https://doi.org/10.1017/S1478951514000443

[36] Holiday, E.B., Dieckmann, N.F., McDonald, T.L., Hung, A.Y., Thomas Jr., C.R. and Wood, L.J. (2016) Relationship between Fatigue, Sleep Quality and Inflammatory Cytokines during External Beam Radiation Therapy for Prostate Cancer: A Prospective Study. Radiation and Oncology, 118, 105-111.

https://doi.org/10.1016/j.radonc.2015.12.015

[37] Fasse, L., Flahault, C., Bredart, A., Dolbeault, S. and Sultan, S. (2015) Describing and Understanding Depression in Spouses of Patients with Cancer in Palliative Phase. Psycho-Oncology, 24, 1131-1137. https://doi.org/10.1002/pon.3777

[38] Akechi, T., Okamura, H., Yamawaki, S. and Uchitomi, Y. (1998) Predictors of Patient's Mental Adjustment to Cancer: Patient Characteristics and Social Support. British Journal of Cancer, 77, 2381-2385. https://doi.org/10.1038/bjc.1998.396

[39] Butler, L.D., Field, N.P., Busch, A.L., Seplaki, J.E., Hastings, T.A. and Spiegel, D. (2005) Anticipating Loss and Other Temporal Stressors Predict Traumatic Stress Symptoms among Partners of Metastatic/Recurrent Breast Cancer Patients. Psy- 
cho-Oncology, 14,492-502. https://doi.org/10.1002/pon.865

[40] Grunfeld, E., Coyle, D., Whelan, T., Clinch, J., Reyno, L., Earle, C.C., Willan, A., Voila, R., Coristine, M., Janz, T. and Glossop, R. (2004) Family Caregiver Burden: Results of a Longitudinal Study of Breast Patients with Cancer and Their Principal Caregivers. Canadian Medical Association Journal, 170, 1795-1801. https://doi.org/10.1503/cmaj.1031205

[41] Lewis, F.M. and Deal, L.W. (1995) Balancing Our Lives: A Study of the Married Couple's Experience with Breast Cancer Recurrence. Oncology Nursing Forum, 22, 943-953.

[42] Siegel, K., Karus, D.G., Raveis, V.H., Christ, G.H. and Mesagno, F.P. (1996) Depressive Distress among the Spouses of Terminally Ill Cancer Patients. Cancer Practice, 4, 25-30.

[43] Hedden, L., Wassersug, R., Mahovlich, S., Pollock, P., Sundar, M., Bell, R.H., Goldenberg, L. and Higano, C.S. (2017) Evaluating an Educational Intervention to Alleviate Distress amongst Men with Newly Diagnosed Prostate Cancer and Their Partners. BJU International, 120, E21-E29.

[44] Hudson, P.L., Trauer, T., Lobb, E., Zordan, R., Williams, A., Quinn, K., Summers, M. and Thomas, K. (2012) Supporting Family Caregivers of Hospitalised Palliative Care Patients: A Psychoeducational Group Intervention. BMJ Supportive \& Palliative Care, 2, 115-120. https://doi.org/10.1136/bmjspcare-2011-000131

[45] Wang, F., Luo, D., Fu, L., Zhang, H., Wu, S., Zhang, M., Zhou, H., Sun, T. and Chen, X. (2017) The Efficacy of Couple-Based Interventions on Health-Related Quality of Life in Cancer Patients and Their Spouses: A Meta-Analysis of 12 Randomized Controlled Trials. Cancer Nursing, 40, 39-47. https://doi.org/10.1097/NCC.0000000000000356

[46] Li, Q. and Loke, A.Y. (2014) A Systematic Review of Spousal Couple-Based Intervention Studies for Couples Coping with Cancer: Direction for the Development of Interventions. Psycho-Oncology, 23, 731-739. https://doi.org/10.1002/pon.3535 
Appendix A. The original 60 -item of social support needs regarding disease and treatment of patients.

Q: Due to patient's disease and treatment, have you ever needed support (such as advice from professionals and patients under similar circumstances, information and services) during the past month regarding the following items?
1) Very much
2) Quite a lot
3) A little
4) Solved by myself
5) Extremely satisfied
6) Not applicable

1 About outpatient visit.

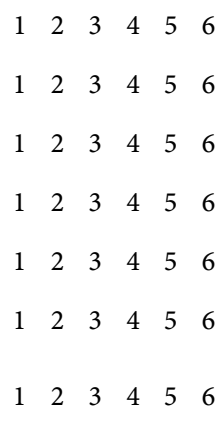

3 Consultation with another specialist besides patient's current doctor about disease and treatment.

4 Having access to professional psychological counseling whenever patient and you needed.

5 Having physical problems of patient not immediately treated to by medical staff (e.g., doctor, nurse).

6 Little sympathy and support concering patient's psychological issues from medical staff.

Poor communication among health care staff to coordinate medical treatment and care of patient (e.g., doctor in charge, other doctors, family doctor and nurses).

8

Not being assured that current hospital or home doctor would provide advice when patients have sudden physical problems at home.

9 Having no particular clinic and doctor that patient or family could consult when patient and family feel the need. $123 \quad 3 \quad 5 \quad 6$

10 Choosing which hospital (or doctor) patient should visit to receive medical treatment and examinations.

$\begin{array}{llllll}1 & 2 & 3 & 4 & 5 & 6\end{array}$

11 Insufficient information about methods, content, and results of medical examinations of patient.

$\begin{array}{llllll}1 & 2 & 3 & 4 & 5 & 6\end{array}$

12 Insufficient information regarding how to obtain information about disease and treatment of patient.

13 Insufficient information about various treatment plans for patient.

$\begin{array}{llllll}1 & 2 & 3 & 4 & 5 & 6\end{array}$

$\begin{array}{llllll}1 & 2 & 3 & 4 & 5 & 6\end{array}$

Insufficient explanations concering benefits and side effects of treatments from medical staff before you decide to have them,

15 Insufficient information regarding complementary and alternative medicine (e.g., health foods, hot springs and qigong etc).

16 Insufficient information regarding palliative medicine and care to decrease distress of patient, such as pain.

17 Insufficient explanation from medical staff about treatment plans and policies.

18 Insufficient information regarding current and prospective medical condition of patient.

19 Insufficient information regarding how to cope with side effects of treatments and disease symptoms.

20 Insufficient information regarding how to take care of patient from now on.

21 Insufficient information regarding appropriate nutrition and diet for patient.

22 Insufficient information regarding how to cope with patient's anxiety and depressive mood.

23 Difficulties for patient in openly communicating with doctor.

24 Getting around and moving of patient (including transportation).

25 Patient looking after self (e.g., eating, bathing, excreting, dressing).

26 Patient taking care of domestic chores for patient (e.g., cleaning, washing, cooking, grocery shopping).

Difficulties in having enough understanding and cooperation from patient's family regarding disease and 


\section{Continued}

28 Taking care of family (e.g., childrearing, nursing parents and spouse).

$\begin{array}{llllll}1 & 2 & 3 & 4 & 5 & 6\end{array}$

9 Imposing a burden on family imposed by patient.

$\begin{array}{llllll}1 & 2 & 3 & 4 & 5 & 6\end{array}$

30 Patient having difficulty dealing with anxiety and worry among family members.

Difficulties in having sufficient support available to you (e.g., assistance and public service from people around you).

32 Difficulties for patient performing responsibilities in the house.

33 Planning patient's and your own future.

34 Issues with pregnancy and childbirth for patient.

35 Being excessively concerned about patient by you.

36 Diffferenecs in opinions about disease and treatment of patient between you and patient.

$\begin{array}{llllll}1 & 2 & 3 & 4 & 5 & 6\end{array}$

$\begin{array}{llllll}1 & 2 & 3 & 4 & 5 & 6\end{array}$

$\begin{array}{llllll}1 & 2 & 3 & 4 & 5 & 6\end{array}$

$\begin{array}{llllll}1 & 2 & 3 & 4 & 5 & 6\end{array}$

$\begin{array}{llllll}1 & 2 & 3 & 4 & 5 & 6\end{array}$

$\begin{array}{llllll}1 & 2 & 3 & 4 & 5 & 6\end{array}$

$\begin{array}{llllll}1 & 2 & 3 & 4 & 5 & 6\end{array}$

37 Talking about patient's disease with patient.

38 Matters concerning your sex life.

39 Relationship and communication with spouse.

40 Relationships and communication with patient's friends and others close to patient.

41 Relationships and communication with patient's neighbors.

42 Talking about patient's disease with people in the patient's workplace and other social places.

43 Patient having no-one with similar experience to talk to.

44 Patient being socially isolated.

45 Having no one or place to go for advice regarding patient's disease and medical treatment.

46 Patient facing discriminatory treatment because of patient's disease.

47 Changes in other people's attitudes and behaviors toward patient.

48 Difficulties enjoying hobbies, recreations and social activities for patient as before because of disease and treatment.

49 Changes in appearance of patient (e.g., increased or decreased weight).

50 Difficulties for patient to return to and maintain to work (or education if patient is a student).

51 Difficulties for patient to ask for time off from work (or school if student) for medical treatment.

$\begin{array}{llllll}1 & 2 & 3 & 4 & 5 & 6\end{array}$

$\begin{array}{llllll}1 & 2 & 3 & 4 & 5 & 6\end{array}$

$\begin{array}{llllll}1 & 2 & 3 & 4 & 5 & 6\end{array}$

$\begin{array}{llllll}1 & 2 & 3 & 4 & 5 & 6\end{array}$

$\begin{array}{llllll}1 & 2 & 3 & 4 & 5 & 6\end{array}$

$\begin{array}{llllll}1 & 2 & 3 & 4 & 5 & 6\end{array}$

$\begin{array}{llllll}1 & 2 & 3 & 4 & 5 & 6\end{array}$

$\begin{array}{llllll}1 & 2 & 3 & 4 & 5 & 6\end{array}$

$\begin{array}{llllll}1 & 2 & 3 & 4 & 5 & 6\end{array}$

$\begin{array}{llllll}1 & 2 & 3 & 4 & 5 & 6\end{array}$

$\begin{array}{llllll}1 & 2 & 3 & 4 & 5 & 6\end{array}$

$\begin{array}{llllll}1 & 2 & 3 & 4 & 5 & 6\end{array}$

$\begin{array}{llllll}1 & 2 & 3 & 4 & 5 & 6\end{array}$

$\begin{array}{llllll}1 & 2 & 3 & 4 & 5 & 6\end{array}$

$\begin{array}{llllll}1 & 2 & 3 & 4 & 5 & 6\end{array}$

$\begin{array}{llllll}1 & 2 & 3 & 4 & 5 & 6\end{array}$

$\begin{array}{llllll}1 & 2 & 3 & 4 & 5 & 6\end{array}$

$\begin{array}{llllll}1 & 2 & 3 & 4 & 5 & 6\end{array}$

$\begin{array}{llllll}1 & 2 & 3 & 4 & 5 & 6\end{array}$

$\begin{array}{llllll}1 & 2 & 3 & 4 & 5 & 6\end{array}$

$\begin{array}{llllll}1 & 2 & 3 & 4 & 5 & 6\end{array}$

$\begin{array}{llllll}1 & 2 & 3 & 4 & 5 & 6\end{array}$

Insufficient information concering social welfare services (e.g., nursing care insurance program, welfare system for the disabled).

59 Insufficient information concerning community health care services availrable to patient (e.g., home visit by a doctor and nurse)

$\begin{array}{llllll}1 & 2 & 3 & 4 & 5 & 6\end{array}$

Insufficient information concerning living supports for patient receiving cancer treatment (e.g., wigs, elastic stockings, wheelchair, adjustable medical bed)

$\begin{array}{llllll}1 & 2 & 3 & 4 & 5 & 6\end{array}$

Items in bold letters were selected and modified for the original 54-item social support needs regarding disease and treatment of patient used in this study. 
Appendix B. The original 22-item of social support needs of spouses.

Q: Have you ever needed support for yourself (such as advice from professionals, similar patients, information and services) during the past month regarding the following items?
1) Very much
2) Quite a lot
3) A little
4) Solved by myself
5) Extremely satisfied
6) Not applicable

1 Little sympathy and support concerning your psychological issues from medical staff. $\begin{array}{llllll}1 & 2 & 3 & 4 & 5 & 6\end{array}$

2 Insufficient information concerning how to cope with your anxiety and depressive mood as a family.

3 Taking care of domestic chores (e.g., cleaning, washing, cooking, grocery shopping).

4 Feeling burdened as a family.

5 Difficulties dealing with your anxiety and worry as family.

6 Difficulties performing your responsibilities in the house.

7 Issues with your pregnancy and childbirth.

8 Being excessively concerned about you by patient.

9 Relationships and communication with your friends and persons close to you.

10 Relationships and communication with neighbors.

$\begin{array}{llllll}1 & 2 & 3 & 4 & 5 & 6\end{array}$

$\begin{array}{llllll}1 & 2 & 3 & 4 & 5 & 6\end{array}$

$\begin{array}{llllll}1 & 2 & 3 & 4 & 5 & 6\end{array}$

$\begin{array}{llllll}1 & 2 & 3 & 4 & 5 & 6\end{array}$

$\begin{array}{llllll}1 & 2 & 3 & 4 & 5 & 6\end{array}$

$\begin{array}{llllll}1 & 2 & 3 & 4 & 5 & 6\end{array}$

$\begin{array}{llllll}1 & 2 & 3 & 4 & 5 & 6\end{array}$

$\begin{array}{llllll}1 & 2 & 3 & 4 & 5 & 6\end{array}$

$\begin{array}{llllll}1 & 2 & 3 & 4 & 5 & 6\end{array}$

11 Talking about patient's disease in your workplace and other social places.

$\begin{array}{llllll}1 & 2 & 3 & 4 & 5 & 6\end{array}$

12 Having no one with similar experience to talk to.

$\begin{array}{llllll}1 & 2 & 3 & 4 & 5 & 6\end{array}$

13 Being socially isolated.

14 Having no one or place to go for advice regarding patient's disease and medical treatment life.

$\begin{array}{llllll}1 & 2 & 3 & 4 & 5 & 6\end{array}$

$\begin{array}{llllll}1 & 2 & 3 & 4 & 5 & 6\end{array}$

15 Facing discriminatory treatment because of patient's disease.

16 Changes in other people's attitudes and behaviors toward you because of patient's disease.

${ }_{17}$ Difficulties enjoying your hobbies, recreations and social activities as before because of disease and treatment of patient.

18 Difficulties for you to return to and maintain to work (or education if patient is a student) because of patient's disease.

19 Difficulties in getting a promotion and advancing in your workplace because of patient's disease.

$\begin{array}{llllll}1 & 2 & 3 & 4 & 5 & 6\end{array}$

$\begin{array}{llllll}1 & 2 & 3 & 4 & 5 & 6\end{array}$

$\begin{array}{llllll}1 & 2 & 3 & 4 & 5 & 6\end{array}$

$\begin{array}{llllll}1 & 2 & 3 & 4 & 5 & 6\end{array}$

$\begin{array}{llllll}1 & 2 & 3 & 4 & 5 & 6\end{array}$

20 Being demoted and assigned a lower position in your workplace because of patient's disease.

$\begin{array}{llllll}1 & 2 & 3 & 4 & 5 & 6\end{array}$

21 Being urged to resign and lose your job.

$\begin{array}{llllll}1 & 2 & 3 & 4 & 5 & 6\end{array}$

22 Insufficient information concering social welfare services (e.g., family care leave, family care leave benefits).

$\begin{array}{llllll}1 & 2 & 3 & 4 & 5 & 6\end{array}$

Items in bold letters were selected and modified for the original 54-item social support needs regarding disease and treatment of patient used in this study. 